existence of nuclear-weapon states (NWS) and NNWS. Much is made of NWS failure to implement Article VI of the NPT. But the extent to which this is hard reality or a cloak to preserve a weapon option is not considered.

Nuclear Power Struggles is confined within its subtitle. It does not enter on wider issues of nuclear energy for a longterm future; in this, one may perhaps be excused for sensing just a whiff of defeatism - something not evident in the attitude of the French. Yet within that restriction, and within the ten-year timeframe, the reader in government, industry or international organizations will find this a useful analysis of nuclear and industrial adjustment. On points of prediction, assessment or 'guestimation' there is scope for challenge, but that does not minimize overall interest in the work presented.

Robert Press was Deputy Secretary, responsible for Science ad Technology, in the UK Cabinet Office from 1974 to 1976 . He is now retired.

\section{Mineral matters}

\section{Roger G. Burns}

Orthosilicates. Vol. 1A of the second edition of Rock-Forming Minerals.

By W.A. Deer, R.A. Howie and

J. Zussman.

Longman: 1982. Pp.912. £50, \$149.95.

THE publication of a new edition of a very successful, widely acclaimed reference text some $15-20$ years after the previous edition always arouses interest and curiosity. Have the authors, now well into or beyond their prime, kept abreast of rapid developments in their field? Have they been able to cope with the voluminous literature published in the intervening years? Are new techniques, data and interpretations successfully assimilated into the text of the earlier edition? Is the revised edition as stimulating and as authoritative as the original? Fortunately, positive responses to these questions apply to two volumes that have appeared to date of the second edition of Rock-Forming Minerals, affectionately referred to by mineralologists as the DHZ volumes.

The original edition, including the five volume treatise Rock-Forming Minerals published in 1962 and the condensed version An Introduction to the RockForming Minerals appearing in 1965 and widely used as an undergraduate textbook, provided a unique compendium of information about properties and occurrences of the most common minerals for over 20 years. Each volume in the first edition dealt with a specific group of structurally related minerals. They were the reference books to which researchers turned first for data on a mineral being studied or for directions to an unsolved or poorly understood mineralogical problem.

However, the current generation of earth scientists, nurtured by the $\mathrm{DHZ}$ volumes, have themselves contributed to the proliferation of new information about minerals and rocks, rendering the first edition out-of-date. During the past two decades automated instrumental methods such as electron microprobe analysers and single crystal diffractometers have been developed, generating voluminous chemical and structural data for minerals; new spectroscopic and electron microscopic techniques have evolved, providing a wealth of new information about the crystal chemistries and microstructures of minerals, and wider ranges of accessible temperatures and pressures have extended experimental investigations of mineral syntheses and stabilities. In attempts to update the expanding data base for minerals, mineralogical societies have been conducting annual short courses and preparing inexpensive typewriter-offset printed volumes devoted to specific mineral groups, as shown by the Reviews in Mineralogy series published by the Mineralogical Society of America. It is against this proliferation of mineralogical data and the publication of competing texts that this second edition will be judged.

Of the two volumes published so far, each represents a bifurcation of an original volume. Vol. 2A, Single-Chain Silicates appeared in 1978 and covered minerals of the pyroxene and pyroxenoid groups. In Vol. 1A, Orthosilicates, minerals of the olivine and garnet groups are exhaustively covered, in addition to the humites, zircon, sphene, vesuvianite, sillimanite, mullite, andalusite, kyanite, topaz, staurolite, and chloritoid. The new editions retain the characteristics of the original volumes. Each mineral is discussed in five sections: structure, chemistry, optical and physical properties, distinguishing features, and paragenesis. Sometimes, additional sections on cation distribution and experimental work are added, reflecting the wealth of new data now available from spectroscopic measurements and mineral synthesis and stability studies. Numerous subheadings throughout the books also help clarify substantial new information. The text has been completely rewritten, and most of the illustrations are new and taken from recent literature. Tables of chemical analyses of each mineral have been expanded to include the plethora of electron microprobe results, and generally contain analytical data for only a few of the specimens described in the first edition.

The hallmark of the original volumes comprehensive but not exhaustive bibliographies for each mineral - is reproduced in the second edition with references to publications as recent as early 1981. The treatment of orthosilicates in Vol. 1A compliments nicely the coverage in Reviews in Mineralogy, Vol. 5. The former contains more petrological information, is better indexed, and more homogeneously written and printed than the latter, which abounds in crystal chemical and structural data for the minerals.

The excellence of the first volumes of the new edition heightens the anticipation of mineralogists for the publication of the rest of the series. They will remain the launching pad for the next generation of researchers of rock-forming minerals.

Roger G. Burns is Professor of Mineralogy and Geochemistry at the Massachusetts Institute of Technology.

\section{Laws for the land}

\section{Richard Macrory}

Planning and Pollution: An examination of the Role of Land Use Planning in the Protection of Environmental Quality.

By Christopher Miller and Christopher Wood.

Oxford University Press: 1983. Pp.232. f15.00, \$32.50.

ONE OF the more remarkable features of the British town and country planning system is the absence in the governing legislation of any clear statement of the purpose of planning controls. And this despite the fact that this field of law provides perhaps the country's most comprehensive intrusion of public control over private property rights.

It is possible to regard this lack of definition as a strength of the system, allowing it to adapt to particular political needs of the day. But one consequence has been an ever-present tension between planning professionals, the courts, Central Government and local planning authorities, as each attempt to redefine or push at the boundaries of current practice. Differing perceptions of the role of planning controls have raised fundamental questions: should planning be confined to questions of land-use conflict or 'amenity'; is it legitimate for planning authorities to investigate the economic viability or necessity of a proposed development; should the system be employed to further more overtly political or social goals, such as the discouragement of second homes, or the promotion of small businesses?

Planning and Pollution examines one area where there might be thought to be less room for conflict - the relationship between land-use planning and pollution controls. But although it was the growth of public health law in the nineteenth century that provided one of the mainsprings for the development of the modern town and country planning system, pollution control laws now represent a distinctive body of specialized legislation. Responsibility for their enforcement often rests with agencies 